\title{
Análise proliferativa nas células trofoblásticas em bovinos ${ }^{1}$
}

\author{
Rose Eli G. Rici2 ${ }^{*}$, Patrícia R. Facciotti², André L.R. Franciolli², Ana Carolina \\ F. Mançanares ${ }^{2}$, Jamila Pastori ${ }^{2}$, Durvanei A. Maria ${ }^{3}$ e Maria Angélica Miglino ${ }^{2}$
}

\begin{abstract}
Rici R.E.G., Facciotti P.R., Franciolli A.L.R., Mançanares A.C.F., Pastori J., Maria D.A. \& Miglino M.A. 2011. [Proliferative analysis of trophoblastic cells in cattle.] Análise proliferativa nas células trofoblásticas em bovinos.] Análise proliferativa nas células trofoblásticas em bovinos. Pesquisa Veterinária Brasileira 31(6):538-542. Programa de Pós-Graduação em Anatomia dos Animais Domésticos e Silvestres, Faculdade de Medicina Veterinária e Zootecnia, Universidade de São Paulo, Av. Prof. Dr. Orlando Marques de Paiva 87, Cidade Universitária, São Paulo, SP 05508-270, Brazil. Email: roseeli@usp.br

The aim of the present study was to evaluate the cell proliferative activity, by AgNORs number, in different regions of bovine placenta throughout gestation. A total of 28 bovine placentas were separated into four groups: group I (60 to 120 days), group II (121 to 170 days), group III (171 to 220 days), and group IV (221 to 290 days). It was found a greater number of AgNORs in giant trophoblastic cells (GTC) when compared with mononuclear trophoblastic cells $(M T C)(p<0,001)$ in all regions and gestational groups analyzed, that confirms their intensive synthesis activity in trophoblast epithelium. The central region of the placentome begins an intense proliferative activity in group II, observed by clusters, while placentomes edges showed a higher number of clusters on group III. These data suggest that the central region of the placentomes began an intense proliferative activity prior to its edge, both declines at the end of pregnancy. Interplacentomal area showed a higher number of AgNORs in the group IV, suggesting a higher proliferative activity of these cells at the end of pregnancy. The results of this study indicate that the proliferative activity, as determined by the amount of intranuclear AgNORs, exhibits patterns that are not only specific to each type of trophoblastic cells, but also for each specific region of bovine placenta throughout pregnancy.
\end{abstract}

INDEX TERMS: Placentome, AgNORs, cell proliferation, cattle.

RESUMO.- Este estudo teve como objetivo analisar atividade proliferativa das células trofoblásticas, através da quantificação de AgNORs, em diferentes regiões da placenta bovina ao longo da gestação. Foram utilizados 28 úteros, sendo estes agrupados de acordo com as idades gestacionais: grupo I (60-120 dias); II (121- 170 dias); III (171-220 dias) e IV (221-290 dias). Foi encontrado um número significativamente maior de AgNORs nas células trofoblásticas gigantes (CTG) em relação às mononucleadas

\footnotetext{
${ }^{1}$ Recebido em 12 de setembro de 2010.

Aceito para publicação em 9 de fevereiro de 2011.

2 Programa de Pós- Graduação em Anatomia dos Animais Domésticos e Silvestres, Faculdade de Medicina Veterinária e Zootecnia (FMVZ), Universidade de São Paulo (USP), Av. Prof. Dr. Orlando Marques de Paiva, 87, Cidade Universitária, São Paulo, SP 05508270. * Autor para correspondência: roseeli@usp.br

${ }^{3}$ Laboratório de Biofísica e Bioquímica, Instituto Butantã, Av. Vital Brasil, 1500, São Paulo, SP 05503-000, Brasil.
}

(CTM) $(p<0,001)$ em todas as regiões e grupos gestacionais analisados, o que confirma sua intensa atividade de síntese no epitélio trofoblástico. A região central do placentônio inicia uma atividade proliferativa mais intensa já no grupo II, observada pelo número de clusters, enquanto que a margem do placentônio apresenta uma maior quantidade de clusters no grupo III. Estes dados sugerem que a região central do placentônio inicia uma intensa atividade proliferativa anteriormente a sua margem, ambas declinando no final da gestação. A área interplacentomal apresentou um maior número de AgNORs no último grupo gestacional, sugerindo uma maior atividade proliferativa dessas células no final da prenhez. Os resultados deste estudo indicam que a atividade proliferativa, determinada pela quantidade de AgNORs intranucleares, exibe padrões que são específicos não somente para cada tipo de célula trofoblástica, mas também para cada região específica da placenta bovina ao longo da gestação. 
TERMOS DE INDEXAÇÃO: Placentônio, AgNORs, proliferação celular, bovinos.

\section{INTRODUÇÃO}

As regiões organizadoras de nucléolos (nucleolar organizer regions, NORs) são segmentos do DNA localizados nas constrições secundárias do cromossomo e estão relacionadas com a síntese de RNA ribossomal, refletindo a atividade sintética das células. Um grupo peculiar de proteínas ácidas que têm alta afinidade por prata é localizado nos mesmos locais que as NORs, o que confere às mesmas a propriedade de serem clara e rapidamente visualizadas por colorações que utilizam nitrato de prata (Goodpasture \& Bloom 1975). Segundo Trerè (2000), quando são coradas por prata, as NORs podem ser facilmente identificadas por pontos negros na área nucleolar, sendo denominadas AgNORs (argyrophilic nucleolar organizer regions). De acordo com o descrito por Crocker et al. (1989), quando os pontos pretos, chamados de dots, se agregam e não se torna possível a identificação de um ponto, cada aglomerado de dots, agora chamados de clusters, podem ser considerados como uma AgNOR.

As AgNORs são unidades estrutural-funcionais do nucléolo nos quais todos os componentes necessários para a síntese do RNA ribossômico (RNAr) estão localizados. O número de AgNORs está estritamente relacionado com a atividade transcricional do RNAr e com a agilidade e rapidez da proliferação celular no tecido estudado (Derenzini \& Ploton 1991). Esta técnica é amplamente utilizada no diagnóstico e prognóstico de muitos tipos de tumores, por caracterizar com grande eficácia a proliferação celular, já que as células cancerosas possuem uma grande quantidade de AgNORs, enquanto que as células de lesões benignas ou normais possuem menor quantidade (Derenzini et al. 1995). A determinação do número e da área das AgNORs tem sido comparada com outros métodos de mensuração da atividade celular, como a determinação da proliferação celular através da citometria de fluxo (Crocker et al. 1988) ou com a utilização de marcadores de proliferação celular, como o Ki-67 (Klisch et al. 1999, Schuler et al. 2000, Hoffmann \& Schuler 2002, Boos et al. 2006) e essa correlação tem mostrado positiva.

O crescimento placentário é complexo e influenciado por diversos fatores, sendo dependente de um balanço adequado entre proliferação, diferenciação e morte celular (Hale et al. 1996, Facciotti et al. 2009). As células trofoblásticas da placenta bovina estão divididas em duas grandes populações: as mononucleadas e as trofoblásticas gigantes, que somam aproximadamente um quinto da população total. Em muitos estudos as células trofoblásticas gigantes são denominadas de binucleadas, sem a utilização do termo "gigante". Porém, segundo Winsatt (1951), Björkman (1969) e Klisch et al. (1999) as células gigantes não são exclusivamente binucleadas, por esta razão utilizamos neste estudo o termo células trofoblásticas gigantes. De maneira geral, as células trofoblásticas produzem diversos hormônios e fatores de crescimento, que estão associados com o crescimento fetal e manutenção da gestação (Schlafer et al. 2000, Rici et al. 2009). O trofoblasto possui propriedades únicas e diversas funções metabólicas, endócrinas e angiogênicas, porém, a atividade proliferativa na placenta bovina e o seu papel no desenvolvimento fetal ainda são pouco conhecidos. O objetivo deste estudo foi analisar a atividade proliferativa das células trofoblásticas, por meio da coloração de prata, em diferentes regiões da placenta bovina ao longo da gestação.

\section{MATERIAL E MÉTODOS}

Foram obtidos 28 úteros gravídicos de vacas mestiças (Bos taurus e Bos indicus) em abatedouro comercial, de diversas fases gestacionais. As medidas cefalococcígeas dos fetos foram utilizadas para determinar a idade de prenhez (Richardson, 1989). Os grupos foram determinados de acordo com as idades gestacionais: grupo I (60-120 dias); II (121-170 dias); III (171-220 dias) e IV (221-290 dias), perfazendo seis animais em cada grupo. Amostras de diferentes regiões placentárias foram coletadas: região central e marginal do placentônio, microplacentônios $(\leq 1,0 \mathrm{~cm})$, área interplacentomal e fusão de placentônios. As amostras foram fixadas em formaldeído 10\% em PBS, emblocadas em paraplast e seccionadas em micrótomo (Leica, Germany).

As lâminas foram imersas em uma solução final 1:2, que consiste de solução coloidal (gelatina $2 \%$ e ácido fórmico $1 \%$ ) e solução de nitrato de prata $(1: 1)$ e levadas à estufa a $37^{\circ} \mathrm{C}$, em câmara úmida, por aproximadamente 20 minutos, dependendo da amostra. Após a lavagem das lâminas com água, aplicou-se a solução de tiossulfato de sódio $1 \%$ por um minuto e procedeu-se a nova lavagem. Em seguida, as lâminas foram secadas a temperatura ambiente e acondicionadas em caixa na ausência da luz. A captura e digitalização das imagens e contagem das AgNORs foi realizada através de microscópio de luz, no sistema CCD-IRIS Sony Company.

Por meio da microscopia ótica visualizaram-se pequenos pontos escuros intranucleares (dots) e aglomerados destes pontos (clusters). O número de AgNORs foi contado em 100 núcleos de células trofoblásticas gigantes e 100 núcleos de células trofoblásticas mononucleadas por corte de tecido. Nas células trofoblásticas gigantes binucleadas a quantidade de AgNORs foi considerada em ambos os núcleos. Foi quantificada individualmente a quantidade de dots e de clusters nos núcleos celulares, além de uma análise do número total de AgNORs em cada tipo celular (dots + clusters). A média e o desvio padrão do número total de AgNORs por célula em cada região foi determinado, utilizando o método estatístico de análise de variância de ANOVA.

\section{RESULTADOS}

A placenta bovina com 76 dias de gestação apresentou caracterizada por diferentes padrões de distribuição de AgNORs (Fig.1A). Pequenos e poucos dots estão presentes nos núcleos das células trofoblásticas mononucleadas, onde cada dot corresponde a um pequeno nucléolo. Nas células trofoblásticas gigantes observamos outro padrão de distribuição das AgNORs, com uma grande quantidade de dots intranucleares e a presença de clusters (aglomerados de dots-Fig1B). 


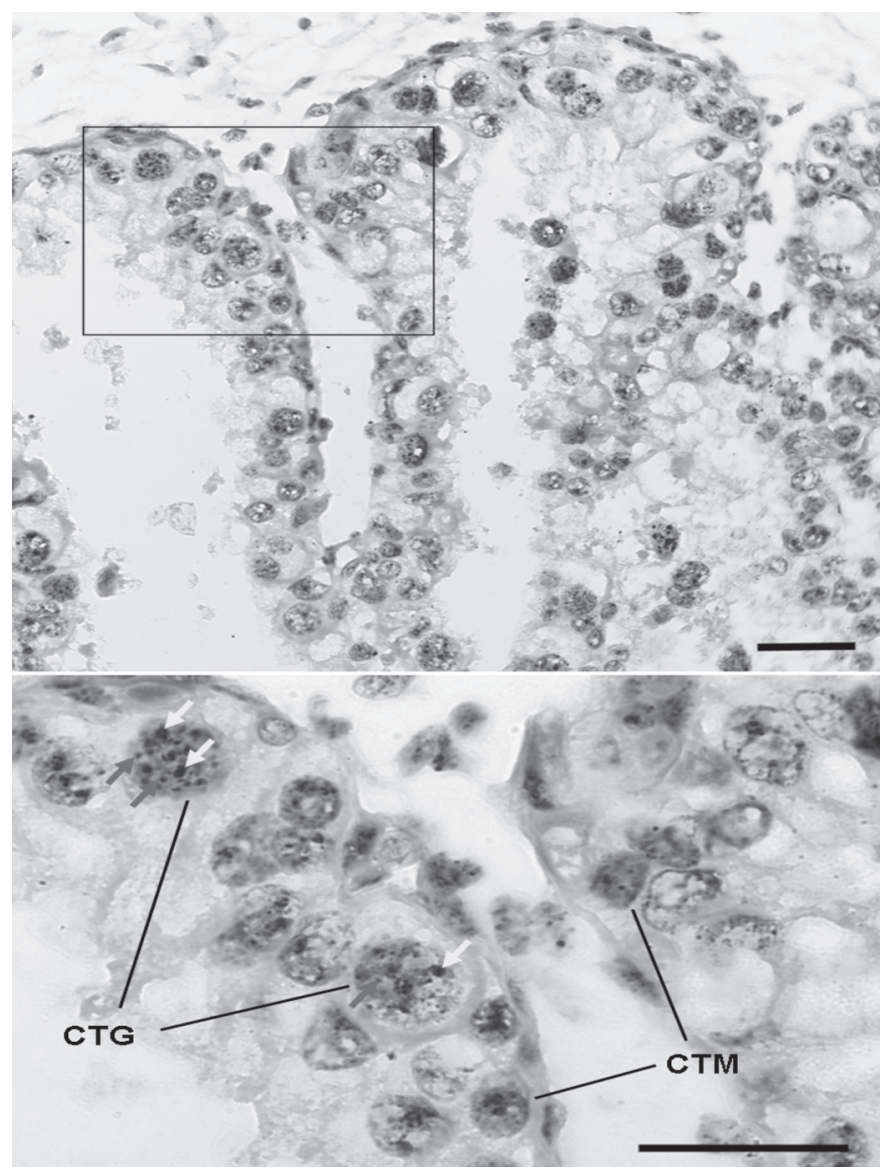

Fig.1. Corte histológico de placenta bovina do grupo I (76 dias), corado com Nitrato de Prata. (A) A maior quantidade de AgNORs nas células trofoblásticas gigantes (CTG) em relação às células trofoblásticas mononucleadas (CTM). (B) Detalhe das AgNORs como pequenos pontos pretos intranucleares - dots (seta verde) ou em aglomerados - clusters

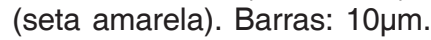

O valores obtidos do número total de AgNORs e individualmente dots e clusters nas células trofoblásticas mononucleadas e gigantes estão descritos nos Quadros 1 e 2, respectivamente. A região central do placentônio apresentou um menor número total de AgNORs no grupo I em relação aos demais grupos gestacionais, tanto nas células trofoblásticas mononucleadas $(\mathrm{p}<0,05)$ como nas gigantes $(p<0,01)$. Na região marginal do placentônio houve variação apenas para as células trofoblásticas gigantes, as quais apresentaram um maior número de AgNORs nos grupos II e III $(p<0,05)$. A área interplacentomal apresentou um maior número total de AgNORs nas células mononucleadas do grupo IV $(p<0,05)$, enquanto que para as células trofoblásticas gigantes não houve variação na quantidade de AgNORs. Os microplacentônios e as fusões placentomais não apresentaram variações significativas na quantidade total de AgNORs em suas células trofoblásticas.

Analisando individualmente a quantidade de dots e clusters observamos algumas variações entre as células trofoblásticas em cada região placentária. A região central do placentônio apresentou uma quantidade significativamen- te menor de dots no grupo I nas células trofoblásticas mononucleadas e também nas células gigantes $(p<0,05)$. A quantidade de clusters, por sua vez, foi significativamente maior nas células trofoblásticas mononucleadas do grupo II $(p<0,05)$ em relação aos demais grupos gestacionais. A região marginal do placentônio apresentou variações na quantidade de dots apenas nas células trofoblásticas gigantes, as quais apresentaram um maior número de AgNORs nos grupos II e III $(p<0,05)$. Ainda nesta região foi observada uma maior quantidade de clusters no grupo III em ambos os tipos celulares $(p<0,05)$, a qual decaiu intensamente no último grupo gestacional.

Poucas variações significativas foram observadas na área interplacentomal, sendo estas apenas na quantidade de dots das células mononucleadas, a qual foi significativamente maior no grupo IV em relação aos demais grupos gestacionais $(p<0,05)$. Nos microplacentônios, as células trofoblásticas mononucleadas apresentaram um número significativamente maior de clusters no grupo III em relação aos demais grupos $(p<0,05)$. Nas células trofoblásticas gigantes o número de clusters também foi significativamente maior nas células do grupo III em relação aos demais grupos gestacionais $(p<0,05)$. Em relação à quantidade de dots, houve diferença significativa apenas nas células trofoblásticas gigantes entre os grupos II e IV que apresentaram, respectivamente, o menor e o maior número de dots $(p<0,05)$. Na região de fusão placentomal não houve variações significativas na quantidade de dots em ambos os tipos celulares ao longo da prenhez. A quantidade de clusters, por sua vez, foi significativamente maior no grupo III nos dois tipos celulares $(p<0,05)$.

\section{DISCUSSÃO}

Foram localizadas AgNORs em todos os tipos celulares do epitélio trofoblástico, com marcação nos núcleos de células mononucleadas e células gigantes, inclusive nas binucleadas. Em uma análise imuno-histoquímica com o antígeno de proliferação Ki-67, Schuler et al. (2000) também observaram marcação positiva nas células mononucleadas e nas células trofoblásticas gigantes. Os mesmos autores encontraram reação positiva também nas células binucleadas. Como as células trofoblásticas gigantes são consideradas como células que não se dividiram completamente, presumivelmente estas células Ki-67 positivas eram células trofoblásticas gigantes imaturas em estágios de multiplicação do genoma (Klisch et al. 1999), fato este que também pode ser relacionado à presença de AgNORs nas células binucleadas.

Todas as regiões analisadas apresentaram um maior número de AgNORs nas células trofoblásticas gigantes do que nas células mononucleadas. Wooding \& Wathes (1980) afirmam que a função normal de uma célula trofoblástica gigante madura em todos os estágios da prenhez de bovinos é a sua migração para o epitélio uterino para a liberação de seus grânulos e em seguida sua condensação a uma célula remanescente, a qual será fagocitada pelo epitélio coriônico. Estas células produzem proteínas e, atra- 


\begin{tabular}{|c|c|c|c|c|c|}
\hline Regiões placentárias & AgNOR & I (60 a 120d) & II (121 a 170d) & III (171 a 220d) & IV (221 a 290d) \\
\hline Região central & DOT & $7.95 \pm 4.78^{a}$ & $14.70 \pm 1.89^{b}$ & $16.58 \pm 1.42^{\mathrm{b}}$ & $14.29 \pm 3.45^{b}$ \\
\hline \multirow{2}{*}{ do placentônio } & CLUSTER & $0.71 \pm 0.76^{a}$ & $2.10 \pm 0.35^{\mathrm{b}}$ & $1.12 \pm 0.49^{a}$ & $0.84 \pm 0.41^{a}$ \\
\hline & TOTAL & $8,65 \pm 5,43^{a}$ & $16,79 \pm 2,23^{b}$ & $17,7 \pm 1,77^{\mathrm{b}}$ & $15,12 \pm 3,18^{b}$ \\
\hline \multirow{3}{*}{$\begin{array}{l}\text { Região marginal } \\
\text { do placentônio }\end{array}$} & DOT & $12.84 \pm 2.99$ & $15.73 \pm 3.03$ & $16.62 \pm 2.82$ & $13.92 \pm 0.67$ \\
\hline & CLUSTER & $1.36 \pm 0.64^{a}$ & $1.77 \pm 0.7^{a}$ & $2.32 \pm 0.62^{b}$ & $1.13 \pm 0.61^{a}$ \\
\hline & TOTAL & $14,2 \pm 3,2$ & $17,5 \pm 3,7$ & $18,9 \pm 2,4$ & $15,0 \pm 0,9$ \\
\hline \multirow[t]{3}{*}{ Área interplacentomal } & DOT & $10.54 \pm 2.9^{a}$ & $9.48 \pm 2.46^{a}$ & $9.45 \pm 2.12^{\mathrm{a}}$ & $14.94 \pm 2.49^{b}$ \\
\hline & CLUSTER & $0.99 \pm 0.81$ & $0.66 \pm 0.91$ & $0.77 \pm 0.32$ & $1.29 \pm 0.24$ \\
\hline & TOTAL & $11,52 \pm 2,93^{a}$ & $10,13 \pm 3,34^{a}$ & $10,21 \pm 2,16^{a}$ & $16,22 \pm 2,57^{b}$ \\
\hline \multirow[t]{3}{*}{ Microplacentônio } & DOT & $14.97 \pm 0.54$ & $15.16 \pm 0.96$ & $16.31 \pm 2.08$ & $14.47 \pm 1.83$ \\
\hline & CLUSTER & $1.23 \pm 0.06^{\mathrm{a}}$ & $1.1 \pm 0.03^{\mathrm{a}}$ & $1.94 \pm 0.61^{b}$ & $1.07 \pm 0.04^{\mathrm{a}}$ \\
\hline & TOTAL & $16,19 \pm 0,4$ & $16,26 \pm 0,9$ & $18,25 \pm 2,1$ & $15,54 \pm 1,5$ \\
\hline \multirow[t]{3}{*}{ Fusão placentomal } & DOT & $13.94 \pm 2.01$ & $15.63 \pm 1.55$ & $17.73 \pm 4.95$ & $15.56 \pm 0.17$ \\
\hline & CLUSTER & $1.72 \pm 0.8^{\mathrm{a}}$ & $0.98 \pm 0.1^{a}$ & $2.48 \pm 0.68^{b}$ & $1.07 \pm 0.01^{\mathrm{a}}$ \\
\hline & TOTAL & $15,66 \pm 1,26$ & $16,61 \pm 1,58$ & $20,21 \pm 5,51$ & $16,62 \pm 0,18$ \\
\hline
\end{tabular}

a-b Valores com letras diferentes em uma mesma linha indicam diferença estatística significante $(p<0,05)$.

Quadro 2. Média e desvio padrão da quantidade de AgNORs nas células trofoblásticas gigantes em diferentes regiões placentárias ao longo da gestação

\begin{tabular}{cccccc}
\hline Regiões placentárias & AgNOR & I $(60 \mathrm{a} 120 \mathrm{~d})$ & II $(121 \mathrm{a} 170 \mathrm{~d})$ & III $(171 \mathrm{a} 220 \mathrm{~d})$ & IV $(221 \mathrm{a} 290 \mathrm{~d})$ \\
\hline Região central & DOT & $15.62 \pm 6.62^{\mathrm{a}}$ & $36.36 \pm 5.84^{\mathrm{b}}$ & $44.44 \pm 6.52^{\mathrm{b}}$ & $36.01 \pm 12.48^{\mathrm{b}}$ \\
do placentônio & CLUSTER & $2.04 \pm 0.69$ & $4.91 \pm 2.93$ & $4.02 \pm 2.03$ & $2.56 \pm 1.03$ \\
& TOTAL & $17,66 \pm 7,27^{\mathrm{C}}$ & $41,28 \pm 8,47^{\mathrm{d}}$ & $48,46 \pm 7,33^{\mathrm{d}}$ & $38,56 \pm 13,44^{\mathrm{d}}$ \\
Região marginal & DOT & $34.08 \pm 9.57^{\mathrm{a}}$ & $50.19 \pm 5.67^{\mathrm{b}}$ & $52.27 \pm 3.58^{\mathrm{b}}$ & $38.79 \pm 11.16^{\mathrm{a}}$ \\
do placentônio & CLUSTER & $4.16 \pm 2.10^{\mathrm{a}, \mathrm{b}}$ & $5.38 \pm 2.46^{\mathrm{a}, \mathrm{b}}$ & $7.19 \pm 1.7^{\mathrm{a}}$ & $2.35 \pm 0.81^{\mathrm{b}}$ \\
& TOTAL & $38,2 \pm 10,5^{\mathrm{a}}$ & $55,9 \pm 8,5^{\mathrm{b}}$ & $59,47 \pm 42^{\mathrm{b}}$ & $41,1 \pm 11,8^{\mathrm{a}}$ \\
Área interplacentomal & DOT & $27.73 \pm 13.62$ & $24.79 \pm 4.09$ & $25.47 \pm 6.54$ & $39.83 \pm 5.68$ \\
& CLUSTER & $2.55 \pm 0.78$ & $1.62 \pm 1.22$ & $2.48 \pm 0.49$ & $2.60 \pm 1.16$ \\
Microplacentônio & TOTAL & $19,23 \pm 13,56$ & $26,40 \pm 4,37$ & $27,95 \pm 7,0$ & $42,44 \pm 6,73$ \\
& DOT & $45.97 \pm 0.9^{\mathrm{a}, \mathrm{b}}$ & $44.54 \pm 3.78^{\mathrm{a}}$ & $46.31 \pm 6.42^{\mathrm{a}, \mathrm{b}}$ & $49.47 \pm 1.68^{\mathrm{b}}$ \\
& CLUSTER & $3.82 \pm 0.51^{\mathrm{a}}$ & $3.1 \pm 0.11^{\mathrm{a}}$ & $5.44 \pm 1.35^{\mathrm{b}}$ & $2.45 \pm 0.47^{\mathrm{a}}$ \\
Fusão placentomal & TOTAL & $49,79 \pm 1,1$ & $47,64 \pm 3,7$ & $51,74 \pm 6,0$ & $51,91 \pm 1,6$ \\
& DOT & $42.8 \pm 8.18$ & $52.16 \pm 3.93$ & $49.59 \pm 14.02$ & $48.50 \pm 2.63$ \\
& CLUSTER & $4.26 \pm 2.17^{\mathrm{a}}$ & $3.73 \pm 1.09^{\mathrm{a}}$ & $6.89 \pm 2.08^{\mathrm{b}}$ & $2.95 \pm 0.54^{\mathrm{a}}$ \\
& TOTAL & $47,06 \pm 6,59$ & $55,89 \pm 3,57$ & $56,49 \pm 16,10$ & $51,44 \pm 2,92$
\end{tabular}

a-b Valores com letras diferentes em uma mesma linha indicam diferença estatística significante $(p<0,05)$.

$c-d$ Valores com letras diferentes em uma mesma linha indicam diferença estatística significante $(p<0,01)$.

vés da liberação de seus grânulos, secretam e transportam substâncias para o organismo materno. Essa intensa atividade de síntese e secreção de substâncias pode explicar a grande quantidade de AgNORs apresentada nestas células, sugerindo uma intensa atividade de síntese entre 171 e 220 dias de gestação.

As células trofoblásticas gigantes apresentaram uma maior quantidade de clusters em relação às células mononucleadas, nas quais os dots foram predominantes. Estes dados sugerem uma maior atividade proliferativa das células trofoblásticas gigantes, já que os clusters estão relacionados a uma proliferação de maneira mais intensa e desordenada nos tecidos (Trerè 2000).

A região central do placentônio apresentou uma menor quantidade de AgNORs no grupo I em todas as células trofoblásticas, demonstrando uma atividade proliferativa menor no início da gestação. Apesar de apresentar uma maior quantidade de AgNORs no grupo III, a única variação estatisticamente significante foi encontrada na quanti- dade de clusters nas células mononucleadas do grupo II, que foi maior neste grupo gestacional. Hoffmann \& Schuler (2002) determinaram a atividade proliferativa através de marcação imunohistoquímica com o antígeno Ki-67 em diversos tipos celulares no placentônio bovino. As células trofoblásticas apresentaram uma maior porcentagem de células positivas no placentônio com 220 dias de gestação, decaindo ao seu menor valor com 240 dias. Estes resultados estão de acordo com o encontrado neste estudo, no qual observamos uma maior quantidade de AgNORs na região central do placentônio no grupo III (171-220 dias), decaindo no último grupo gestacional. Porém, quando analisamos individualmente as células trofoblásticas, observamos que a maior atividade proliferativa ocorre nas células trofoblásticas gigantes, com um valor maior que o dobro do encontrado nas células mononucleadas.

Na margem do placentônio, o maior número total de AgNORs foi observado nos grupos II e III nas células trofoblásticas gigantes, enquanto que a quantidade de clus- 
ters foi significativamente maior no grupo III nos dois tipos celulares. Analisando o placentônio como um todo, observamos que a região central inicia uma atividade proliferativa mais intensa no grupo II, observada pelo número de clusters, enquanto que a margem do placentônio apresenta uma maior quantidade de clusters no grupo III. Estes dados sugerem que a região central do placentônio inicia uma intensa atividade proliferativa, em prior a sua margem, as quais declinam este numero no final da gestação.

Os microplacentônios e fusões placentomais não apresentaram variações significantes no número total de AgNORs ao longo da gestação, apenas na análise individual entre dots e clusters. Ambas as regiões apresentaram uma maior quantidade de clusters no grupo III, sugerindo uma intensa atividade proliferativa neste período gestacional.

A área interplacentomal apresentou um padrão diferenciado na quantidade de AgNORs ao longo da gestação, com valores que permaneceram sem alteração significativa até 220 dias de prenhez, o que é consistente com a composição uniforme do trofoblasto bovino nesta região durante a maior parte da gestação (Wooding \& Wathes,1980). Nesta região houve um aumento no número total de AgNORs apenas no último grupo gestacional. Em uma análise individual entre a quantidade de dots e clusters nas células trofoblásticas interplacentomais, observamos um maior número de AgNORs no último grupo gestacional, sugerindo uma maior atividade proliferativa dessas células no final da prenhez. Este equilíbrio na atividade proliferativa da região interplacentomal na maior parte da gestação pode estar relacionado com o estudo realizado por Boos et al. (2006), que utilizaram a marcação com Ki-67 nas células da região interplacentomal. Estes autores sugerem que a proliferação celular não é o principal fator responsável pelo crescimento da massa uterina interplacentomal, na qual não foram encontradas diferenças significativas na quantidade de células marcadas no epitélio trofoblástico.

Os resultados deste estudo indicam que a atividade proliferativa, determinada pela quantidade de AgNORs intranucleares, exibe padrões que são específicos não somente para cada tipo de célula trofoblástica, mas também para cada região específica da placenta bovina ao longo da gestação.

\section{REFERÊNCIAS}

Björkman N.H. 1969. Light and electron microscopic studies on cellular alterations in the normal bovine placentome. Anat. Rec. 163:1730.

Boos A., Kohtes J., Janssen V., Mülling C., Stelljes A., Zerbe H., Hässig M. \& Thole H.H. 2006. Pregnancy effects on distribution of progesterone receptors, oestrogen receptor $\alpha$, glucocorticoid receptors, Ki-67 antigen and apoptosis in the bovine interplacentomal uterine wall and foetal membranes. Anim. Reprod. Sci. 91:55-76.

Crocker J., Macartney J.C. \& Smith P.J. 1988. Correlation between DNA flow cytometric and nuclear organizer region data in nonHodgkin's lymphomas. J. Pathol. 154:151-156.

Crocker J., Boldy D.A.R. \& Egan M.J. 1989. How should we count AgNORs: Proposals for a standardized approach. J. Pathol. 158:185188.

Derenzini M., Sirri V., Trerè D. \& Ochs R.L. 1995. The quantity of nucleolar proteins nucleolin and protein B23 is related to cell doubling time in human cancer cells. Lab. Invest. 73:497-502.

Derenzini M. \& Ploton D. 1991. Interphase nuclear organizer regions in cancer cells. Int. J. Exp. Pathol. 32:150-192.

Facciotti P.R., Rici R.E., Maria D.A., Bertolini M., Ambrósio C.E., Miglino M.A. 2009. Patterns of cell proliferation and apoptosis by topographic region in normal Bos taurus vs. Bos indicus crossbreeds bovine placentae during pregnancy. Reprod Biol Endocrinol 7:25.

Goodpasture C. \& Bloom S.E. 1975. Visualization of nucleolar organizer regions in mammalian chromosomes using silver staining. Chromosoma 20:37-50.

Hale A.J., Smith C.A., Sutherland L.C., Stoneman V.E., Longthorne V.L., Culhane A.C. \& Williams G.T. 1996. Apoptosis: Molecular regulation of cell death. Eur. J. Biochem. 236:1-26.

Hoffmann C. \& Schuler B. 2002. The bovine placenta, a source and target of steroid hormones: Observations during the second half of gestation. Domestic Anim. Endocrinol. 23:309-320.

Klisch K., Pfarrer C., Schuler G., Hoffmann B. \& Leiser R. 1999. Tripolar acytokinetic mitosis and formation of feto-maternal syncytia in the bovine placentome: Different modes of the generation of multinuclear cells. Anatomy and Embryology 200:229-237.

Klisch K., Hecht W., Pfarrer C., Schuler G., Hoffmann B. \& Leiser R. 1999. DNA content and ploidy level of bovine placentomal trophoblast giant cells. Placenta 19:340-347.

Richardson C. 1989. Personal communication, p.49-59. In: Arthur G.H., Noakes D.E. \& Pearson H. (Eds), Veterinary Reproduction and Obstetrics. $6^{\text {th }}$ ed. Bailliére Tindall, London.

Rici R.E., Facciotti P.R., Ambrósio C.E., Maria D.A., Kfoury J.R. Jr, Bertolini M., Miglino M.A. 2009. Cell cycle and apoptosis in normal and cloned bovine near-term placentae. Anim Reprod Sci. 115(1-4): 29-38.

Schlafer D.H., Fischer P.J. \& Davies C.J. 2000. The bovine placenta before and after birth: Placental development and function in health and disease. Anim. Reprod. Sci. 60/61:145-160.

Schuler G., Wirth C., Klisch K., Failing K. \& Hoffmann B. 2000. Characterization of proliferative activity in bovine placentomes between day 49 and parturition by quantitative immunohistochemical detection of Ki67-antigen. Reprod. Domestic Anim. 24:4651.

Trerè D. 2000. AgNOR staining and quantification. Micron 31:127-131.

Wimsatt W.A. 1951. Observations on the morphogenesis, cytochemistry, and significance of the binucleate giant cells of the placenta of ruminants. Am. J. Anat. 89:233-281.

Wooding F.B.P. \& Wathes D.C. 1980. Binucleate cell migration in the bovine placentome. J. Reprod. Fertility 59:425-430. 